\title{
Measurement of water content of quartz in granitic rocks with micro- FT-IR analysis
}

\author{
K. OMIYA ${ }^{1 *}$ AND M. TSUBOI ${ }^{1}$ \\ ${ }^{1}$ School of Science and Technology, Kwansei Gakuin \\ University, 2-1 Gakuen, Sanda, Hyogo, 669-1337, Japan \\ (*correspondence: dze09747@kwansei.ac.jp)
}

Water and volatile components play an important role for the magma process of the granitic rocks. Quartz is one of the most abundant minerals in the granitic rocks. In general, water in minerals exists in the form of $\mathrm{H}_{2} \mathrm{O}$ molecules or $\mathrm{OH}$ species. $\mathrm{H}_{2} \mathrm{O}$ molecules in minerals exist in the form of fluid inclusions, bound water or structured water. Quartz is an anhydrous mineral, however, it contains a few water. In this study, water content of quartz in granitic rock samples were measured by micro-FT-IR spectroscopy. Measured samples were medium-grained hornblende-biotite tonalite of the Cretaceous Katsuragi tonalite, and fine-grained biotitehornblende granodiorite of the Miocene Goto granites from southwestern Japan. $\mathrm{SiO}_{2}$ content of the Katsuragi tonalite and Goto granites sample are 61.40 wt.\% and 73.98 wt.\%, respectively $[1,2]$. Double polished thin sections with the thickness of 75-120 $\mu \mathrm{m}$ were prepared for the granite samples. Micro-FT-IR spectra of quartz were measured with an aperture size of $10 \times 10 \mu^{2}$. The baseline was drawn between the obtained absorbance of $3000 \mathrm{~cm}^{-1}$ and $3800 \mathrm{~cm}^{-1}$. The absorbance of water was measured at $3400 \mathrm{~cm}^{-1}$. Water content of quartz was estimated using Lambert-Beer's law with the value of $\varepsilon$ of $81 \mathrm{~L} / \mathrm{mol} \cdot \mathrm{cm}$ [3]. Measurement on the grain boundary was excluded. On the analysis of Katsuragi tonalite, some measurement points in quartz grain shows sporadic higher water contents of 100-300 ppm, which may be due to the local existence of fluid inclusions. Water content of quartz grain adjacent to biotite shows 59-79 ppm. Water content of quartz adjacent to quartz is 53-76 ppm. Water content of quartz adjacent to plagioclase shows a higher value of 300-600 ppm. On this condition, unknown characteristic peak of $3500 \mathrm{~cm}^{-1}$ was found. On the analysis of Goto granites, water content of quartz grain adjacent to quartz is $230-1130 \mathrm{ppm}$. Water content of quartz in the Goto granites is higher than that in the Katsuragi tonalite. Water content of quartz in granitic rocks may be affected by grain size, adjacent mineral or whole-rock chemical composition.

[1] Tezuka (2017) M. Sc. thesis of Kwansei Gakuin University, Japan.

[2] Koga (2019) B. Sc. thesis of Kwansei Gakuin University, Japan.

[3] Thompson (1965) Trans. Faraday Soc 61, 1635-1640. 